\title{
Effect of dehydration on phenolic compounds and antioxidant activity of blackcurrant (Ribes nigrum L.) pomace
}

\begin{abstract}
This study examined the effect of dehydration on the phenolic compounds and antioxidant activity of blackcurrant (Ribes nigrum L.) pomaces (DBP) subjected to hot air oven drying (HOD), industrial rotary drying (IRD) and freeze drying (FD). Temperature and residence time were evaluated for HOD, whereas air-on and air-off temperature, ratio of drum rotor speed to air speed and particle size were evaluated for IRD. The highest total anthocyanins (ATC) and flavonols (FLV) were obtained in particle size of $>5.0 \mathrm{~mm}$ using IRD at $475^{\circ} \mathrm{C} / 97^{\circ} \mathrm{C}$ (air-on/airoff) and higher ratio of drum rotor speed to air speed. Smaller size particles were found susceptible to degradation due to high temperature and retention time applied in IRD, resulting in loss of phenolic compounds in DBP, and thus, HOD was deemed more suitable. Overall, drying method selection and parameters of operation are key in preserving the concentrations of individual HCA and FLV in DBP.
\end{abstract}

